\title{
ESCOLARIZAÇÃO DE ALUNOS COM SÍNDROME DE DOWN: UM ESTUDO DE CASO
}

\author{
Regiane Rodrigues Marques ${ }^{1,}$ Angela Maria Hartmann ${ }^{2}$ \\ ${ }^{1}$ Pós-Graduada em Educação: Interdisciplinaridade e Transversalidade da Universidade Federal do Pampa- Unipampa. \\ regimarques2010@hotmail.com \\ ${ }^{2}$ Professora Adjunta da Unipampa, Campus de Caçapava do Sul \\ angelahartmann@unipampa.edu.br
}

\section{RESUMO}

Este artigo apresenta os resultados de um estudo de caso sobre a atitude, em relação ao processo de escolarização, de uma jovem de quinze anos com Síndrome de Down. A jovem é aluna do segundo ano do Ensino Fundamental de uma escola municipal da cidade São Gabriel, Rio Grande do Sul. A fundamentação teórica constitui-se de análise da literatura referente ao tema. Como metodologia, adotou-se a observação direta e diária, durante um mês, acompanhada de anotações em um diário de bordo, das reações da jovem com Síndrome de Down ao seu processo de escolarização. Relata-se a análise do estudo de caso, considerando as atitudes da aluna frente às situações de aprendizagem e a ação metodológica empregada para a construção de seus conhecimentos sob a perspectiva interdisciplinar. Os resultados deste estudo de caso mostram que a jovem apresenta grande dificuldade em grafar as letras. No entanto, reconhece todo o alfabeto, pronunciando-o oralmente. Não apresenta coordenação motora para pintar e tem alternância de humor, sendo, por vezes, muito dócil e, em outras ocasiões, irrita-se com facilidade. A jovem necessita de uma acompanhante pessoal para auxiliá-la nas atividades dentro e fora de sala de aula. Observou-se, também, que a ação educativa não se articula de forma interdisciplinar.

Palavras-chave: Síndrome de Down. Escolarização. Inclusão.

\section{ABSTRACT}

This article presents the results of a case study on the attitude towards the process of schooling, a fifteen year old with Down Syndrome. The girl is a student of second year of elementary school of a public school in the city São Gabriel, Rio Grande do Sul. The theoretical framework consists of analysis of literature on the subject. The methodology adopted to direct observation and daily for a month, accompanied by notes in a logbook, the reactions of the young man with Down Syndrome to their schooling process. We report the analysis of the case study, considering the attitudes of student facing situations of learning and action methodology employed to build their knowledge in an interdisciplinary perspective. The results of this case study show that the girl had difficulties to spell the letters. However, recognize the entire alphabet, pronouncing it orally. It has no motor skills to paint and has alternation of humor, and sometimes, very sweet and at other times, chafes at ease. The young person needs a personal attendant to assist her in activities inside and outside the classroom. There was, also, that the educational activity does not extend in an interdisciplinary way.

Keywords: Down syndrome. Schooling. Inclusion. 


\section{INTRODUÇÃO}

O sistema educacional contemporâneo tem realizado uma busca por respostas para as discussões sobre o processo inclusivo, iniciado em 1990. O objetivo dessas ações é proporcionar a equidade de oportunidades às pessoas com necessidades educacionais especiais. Para tal, procuram-se subsídios teóricos para garantir a qualidade dessas ações.

Os conhecimentos sobre Síndrome de Down começaram no século XIX, e novos estudos surgem, constantemente com propostas inovadoras sobre o tema. Através de pesquisas realizadas sobre a evolução dos estudos sobre a síndrome, verifica-se um fato muito curioso e importante, que é a imagem que a sociedade produziu, por muitos anos, sobre as pessoas que apresentam esta Síndrome.

Por um longo período, a criança com Síndrome de Down foi considerada como uma pessoa retardada e incapaz. Em algumas sociedades, era considerada como um monstro ou um filho do demônio (LIMA; FERRAZ, 2000) Mas isso não ficou só no passado, infelizmente, ainda encontram-se algumas distorções em relação ao conceito de Down, que é muito confundido com deficiência mental. Lima e Ferraz (2000) deixam claro que, em estudos recentes sobre os conceitos saúde-doença, inclusão-exclusão e representações sociais relacionadas à Síndrome de Down, verificaram-se a presença de ideias estigmatizadas e rotulação em relação à pessoa com Síndrome. Portanto, devido a estas constatações, recomendam a necessidade de uma formação adequada dos profissionais envolvidos no trabalho com pessoas com Síndrome de Down, no sentido de melhor preparação para lidar com as diferenças inerentes às suas capacidades cognitivas.

Com o objetivo de examinar como é a atitude da aluna diante das situações de aprendizagem que lhes são feitas em sala de aula e como ela responde a elas, este artigo apresenta um estudo de caso, que foi realizado com uma aluna com Necessidade Educacional Especial, Síndrome de Down (NEE - SD),

O referencial teórico que orienta e ordena as análises deste presente trabalho parte de breves considerações sobre escolarização de alunos com Necessidades Especiais, em especial aquelas com Síndrome de Down, apresentando conceituações, destacando os aspectos congênitos e as principais características do desenvolvimento cognitivo da criança Down. Também discute a interdisciplinaridade no contexto da inclusão escolar.

\section{ESCOLARIZAÇÃO DE ALUNOS COM NECESSIDADES ESPECIAIS}

A proposta de inclusão surgiu no início do século $\mathrm{XX}$, momento em que as pessoas com deficiências passaram a ser consideradas cidadãos com direitos e deveres. Isso foi expresso por intermédio de diversos documentos que surgiram, sendo o primeiro deles de 1948, no qual se torna pública a Declaração Universal dos Direitos Humanos. Com base nesse documento, as famílias destas pessoas iniciaram alguns debates e organizaram-se, realizando, então, as primeiras críticas sobre a segregação. Surgiam daí os movimentos em prol da inclusão.

No Brasil, a educação especial enquadrou-se no sistema geral de educação com a aprovação da Lei no 4.024/61, contemplando o atendimento às pessoas com deficiências, quando possível no sistema regular de ensino.

Em 1989, foi aprovada a lei no 7.853/89, que prevê, no item "educação", a oferta obrigatória e gratuita da educação especial em estabelecimentos públicos de ensino, prevendo, também, punições para dirigentes de ensino público ou particular que se recusem a matricular 
alunos que apresentem algum tipo de deficiência, ou mesmo suspendam, sem justa causa, a sua permanência na escola.

O Estatuto da Criança e do Adolescente reiterou os direitos garantidos na constituição de 1988 e o atendimento especializado para pessoas com necessidades educacionais especiais, preferencialmente na rede regular de ensino. Porém, o marco fundamental para desencadear de vez o processo de inclusão foi a Declaração de Salamanca (1994), que se constitui num suporte pedagógico utilizado atualmente, pois apresenta linhas de ação para garantir igualdade de oportunidades e, desse modo, efetivar o processo inclusivo que, por vezes, está sendo confundido com integração ${ }^{1}$ (MANTOAN, 1997)

As Diretrizes Nacionais para a Educação Especial na Educação Básica constituem outra fonte de orientação sobre o processo de inclusão escolar de crianças e jovens com NEE

\begin{abstract}
A inclusão escolar constitui uma proposta que representa valores simbólicos importantes, condizentes com a igualdade de direitos e de oportunidades educacionais para todos, mas encontra ainda sérias resistências. Estas se manifestam, principalmente, contra a ideia de que todos devem ter acesso garantido à escola comum. A dignidade, os direitos individuais e coletivos garantidos pela constituição Federal (1988) impõem às autoridades e à sociedade brasileira a obrigatoriedade de efetivar essa política, como um direito público subjetivo, para o qual recursos humanos e materiais devem ser canalizados, atingindo, necessariamente, toda a educação básica (BRASIL, 2001, p. 26).
\end{abstract}

Cabe ressaltar que a política de inclusão de alunos com necessidades educacionais especiais na rede regular de ensino não consiste apenas na permanência física desses alunos junto aos demais, mas "representa a ousadia de rever concepções e paradigmas, bem como desenvolver o potencial dessas pessoas, respeitando suas diferenças e atendendo suas necessidades (BRASIL, 2001, p. 28).

Nesse sentido, a escola deve proporcionar ao aluno condições para que ele possa desenvolver suas potencialidades, pois desta forma, não é o aluno que se molda ou se adapta à escola, mas é ela que, consciente de sua função, coloca-se à disposição do aluno, tornando-se um espaço inclusivo. Nesse contexto, a educação especial é concebida para possibilitar que os alunos com deficiências atinjam os objetivos da educação geral (Idem).

Portanto, as modificações diárias pelas quais o mundo convive impulsionam mudanças nas instituições sociais, dentre elas está a escola. Segundo Mattos

Novos paradigmas surgem, tendo em vista a inclusão escolar. Assim, a escola necessita trabalhar as diferenças, para que enriqueçam o aprendizado de todos, deficientes ou não. A diferença é normal, é identidade de cada ser humano. A diferença é produzida diariamente. A diferença é o estereótipo, o arquétipo atual (MATTOS, 2008, p. 51)

A escola deve ter como foco tratar todas as crianças respeitando suas particularidades e diferenças. Essas peculiaridades e diferenças revelam o seu nível de desenvolvimento e caracterizam cada uma na sua singularidade dentro de uma pluralidade encontrada no cotidiano escolar e, em particular, na sala de aula. Nesse sentido, acredita-se que existe a probabilidade de outra pessoa interferir no desenvolvimento ou não do educando, e procura-se na afetividade o elo que possibilita a interação social, não só no ambiente escolar, mas em especial na sala de aula, onde o educador se constitui no mediador e facilitador da sociabilidade do educando.

\footnotetext{
${ }^{1}$ Entende-se por integração a inserção pura e simples das pessoas com necessidades educacionais especiais, sem que haja nenhuma adaptação específica do contexto para o desempenho de tais atividades, utilizando-se para isso somente os recursos previamente disponíveis.

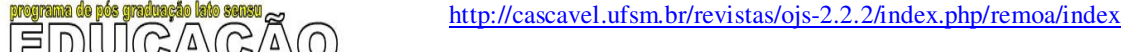


No entendimento de Gotti (1998), o processo de inclusão escolar não está somente direcionado para o aluno com necessidades educacionais especiais, mas também deve trabalhar para incluir o aluno dito normal, que muitas vezes é privado de estar em um ambiente escolar, por motivos vários envolvendo questões sociais, econômicas e culturais.

Tanto a escola de qualidade quanto a educação inclusiva buscam modificações necessárias para que todas as crianças exerçam o seu direito à educação, mas para isso é necessário refletir sobre padrões e comportamentos, modificando papéis e responsabilidades, desenvolvendo uma aproximação entre professor e aluno de modo que o primeiro seja capaz de perceber as necessidades e dificuldades deste.

\section{SÍNDROME DE DOWN}

A Síndrome de Down define-se como sendo consequência de uma alteração genética, que pode ocorrer durante ou imediatamente após a concepção. Essa alteração genética caracteriza-se pela presença a mais do autossomo 21. Isso significa que ao invés de o indivíduo apresentar dois cromossomos 21, ele apresenta três, o que se denomina, em genética, de trissomia simples. Todo o desenvolvimento e a maturação do organismo e inclusive a cognição do indivíduo são alterados com essas alterações genéticas conferindo características específicas relacionadas a essa síndrome (SCHWARTZMAN, 2007).

Características comportamentais dos indivíduos com síndrome de Down, de acordo com Schwartzman (2007):geralmente são calmos, afetivos, bem-humorados com prejuízos cognitivos, mas que em alguns casos podem apresentar variações comportamentais. Assim, a personalidade varia muito de indivíduo para indivíduo, podendo apresentar distúrbios de comportamento. A atitude de um sujeito com síndrome de Down pode variar de acordo com o seu potencial genético e as características culturais do meio em que convive.

Em sujeitos com Síndrome de Down o desenvolvimento físico é mais lento, sendo que a maior parte deles tem retardo mental de leve a moderado. Alguns não apresentam retardo e se situam entre as faixas limítrofes e médias baixas da capacidade intelectual, porém outras podem apresentar retardo mental severo (SCHWARTZMAN, 2007).

De acordo com Werneck (1995), as pessoas com Síndrome de Down costumam ter acentuada inteligência emocional, por isso na maioria das vezes se mostram amáveis e carinhosos.

O sistema nervoso da criança com Síndrome de Down apresenta anormalidades estruturais e funcionais (JOAQUIM, 2006). Estudos realizados por neurologistas concluíram existir uma lesão difusa, acompanhada de um funcionamento elétrico peculiar no desenvolvimento cognitivo da Síndrome de Down, acarretando em um rebaixamento nas habilidades de análise, síntese e a fala comprometida. Sujeitos com síndrome de Down apresentam, ainda, dificuldades em selecionar e direcionar um estímulo devido à fadiga das conexões neuronais. Essas anomalias resultam em disfunções neurológicas, variando quanto à manifestação e intensidade (.SCHWARTZMAN, 2007),

Outros estudiosos como Wisniewski (apud SCHWARTZMAN, 2007), afirmam que todos os neurônios formados são afetados na maneira como se organizam em diversas áreas do sistema nervoso e não só há alterações na estrutura formada pelas redes neuronais, mas também nos processos funcionais da comunicação de um neurônio com o outro. Enfatizam, também, o quanto essas alterações podem influenciar no desenvolvimento inicial dos circuitos cerebrais, prejudicando a instalação e a consolidação das conexões das redes nervosas necessárias para 
estabelecer os mecanismos da atenção, memória, capacidade de correlação e análise, pensamento abstrato, entre outros. De acordo com Schwartzman (2007, p. 54):

\begin{abstract}
Nas pessoas com essa síndrome, existe uma redução na transmissão e comunicação de muitos sistemas neuronais. A criança com a síndrome pode apresentar dificuldades para fixar o olhar devido à lentidão e seu baixo tono muscular, precisando de estímulos e meios para desenvolver a capacidade de atenção. (...) nas crianças mais velhas foram observadas anormalidades nos neurônios piramidais pequenos, especialmente nas camadas superiores do córtex (...).
\end{abstract}

Sabe-se que o desenvolvimento e maturação do sistema nervoso é um processo complexo. O sistema nervoso central da criança com Síndrome de Down, apresenta alterações no desenvolvimento desde a fase fetal (SCHWARTZMAN, 2007),

Segundo Schwartzman (2007, p. 51), as "medidas de inteligência geral e as habilidades linguísticas normalmente encontram-se alterados e estas não possuem padrão definido, além de não se relacionarem com o volume encefálico podendo apresentar em diversos níveis intelectuais". Também se observa no sistema nervoso do paciente Down, alterações de hipocampo e a partir do quinto mês de vida quando se inicia o processo de desaceleração do crescimento e desenvolvimento do sistema nervoso, ocorre uma diminuição da população neural.

Bissoto (2005) afirma que entre as dificuldades a serem consideradas no que diz respeito ao desenvolvimento cognitivo e linguístico, estão o atraso no desenvolvimento da linguagem, dificuldades em reconhecer regras gramaticais e sintáticas da língua. Os sujeitos também manifestam dificuldades na produção da fala com descompasso entre a velocidade com que compreendem e $\mathrm{o}$ ato de falar propriamente dito. Essas dificuldades de linguagem podem afetar outras habilidades cognitivas.

Pesquisa de Cusin et al. (2005) destaca que as características peculiares da Síndrome de Down, conjuntamente com traços pessoais e desempenhos individuais, implicam numa variedade de desempenhos linguísticos. As autoras afirmam que "no que tange esta variabilidade, e atraso do desenvolvimento das funções comunicativas para todas as crianças, o desenvolvimento linguístico esteve atrasado e houve discrepância entre a capacidade receptiva e expressiva" (Idem, 2005, p. 93).

A variedade de lesões que acometem os indivíduos com Síndrome de Down influencia o desenvolvimento e a aprendizagem. Há diferenças significativas no desenvolvimento em função da educação e do ambiente aos que estão submetidas essas crianças desde os primeiros anos de vida, portanto, as generalizações quanto à sua capacidade de aprendizagem podem ser errôneas. Contudo, pode-se estar de acordo com a relativa constância que se apresenta nas crianças com Síndrome de Down quanto a pouca iniciativa, dificuldade em manter a atenção e tendência à distração. (MOELLER, 2006).

Crianças com Síndrome de Down possuem idade cronológica diferente da idade funcional (SCHWARTZMAN, 2007). Portanto, não se pode esperar uma resposta semelhante à resposta daquelas que não apresentam a síndrome e não apresentam alterações de aprendizagem.

A preparação para a aprendizagem está muito condicionada à complexa integração dos processos neurológicos e da harmoniosa evolução das funções específicas como linguagem, percepção, esquema corporal, orientação têmporo-espacial e habilidade.

Fica evidente, na literatura analisada, que o desenvolvimento de crianças com Síndrome de Down não ocorre de forma espontânea. Não é um processo linear e, portanto, impossível de predizer. Dois aspectos influenciam fortemente o desenvolvimento cognitivo; aspectos exteriores 
(um ambiente estimulante, com muitas atividades), assim como aspectos interiores (motivação e processos interativos). Eles constituem uma reabilitação ecológica, pois é comum se observar na criança Down, severas alterações de internalizações de conceitos de tempo e espaço, que dificultarão muitas aquisições e refletirão especialmente em memória e planificação, além de causar muita dificuldade na aquisição da linguagem (WERNECK, 1995).

Em Bissoto (2005) encontra-se a defesa de que a ação educacional ou terapêutica adotada com as crianças com Síndrome de Down precisa considerar, primeiramente, que existem necessidades educacionais próprias, as quais devem ser reconhecidas e respeitadas, para que sejam trabalhadas adequadamente, estimulando e desenvolvendo o indivíduo.

Os profissionais necessitam compreender que existem processos de desenvolvimento particulares de cada indivíduo, porque crianças especiais como as portadoras de Síndrome de Down, não desenvolvem estratégias espontâneas e este é um fato que deve ser considerado em seu processo de aquisição de aprendizagem, já que esta criança ou jovem terá muitas dificuldades em resolver problemas e encontrar soluções sozinhas.

Existem outras deficiências presentes na criança com Síndrome de Down que resultam em dificuldades na aprendizagem, tais como: alterações auditivas e visuais, incapacidade de organizar atos cognitivos e condutas, debilidades de associar e programas sequências. Observa-se que essas dificuldades acontecem devido a imaturidade nervosa e a não mielinização das fibras, o que dificulta o desenvolvimento de funções mentais como: habilidade para usar conceitos abstratos, memória, percepção geral, habilidades que incluam imaginação, relações espaciais, esquema corporal, habilidade no raciocínio, estocagem do material aprendido e transferência na aprendizagem. O pouco desenvolvimento dessas funções dificulta a aprendizagem escolar. No entanto, essas limitações não impossibilitam a criança com Síndrome de Down de executar atividades diárias e até mesmo adquirir formação profissional e desenvolver a linguagem e as atividades como a leitura e escrita.

Schwartzman (2007) e Werneck (1995) sugerem que seria interessante considerar a compreensão do fenótipo como uma reflexão de forças, um padrão compensatório que deve se constituir de áreas de maior competência, que promovem adaptação. Dessa forma, a organização de um trabalho de intervenção deveria estar direcionada aos talentos e interesses, da mesma forma como se devem trabalhar as dificuldades, favorecendo que a pessoa com Down reconheça suas capacidades.

\section{INTERDISCIPLINARIDADE NO CONTEXTO DA INCLUSÃO ESCOLAR}

A fragmentação das disciplinas é problema de ordem prática enfrentado pelos profissionais de diferentes áreas do conhecimento. No entanto, a colaboração entre disciplinas e profissionais docentes, pode contribuir significativamente para a solução de problemas causados por essa fragmentação.

No Brasil, há produção de diversos trabalhos acadêmicos e científicos referentes à importância da interdisciplinaridade. No entanto, a discussão a respeito de sua conceituação vem se arrastando há décadas, sendo escassos os registros de relatos de práticas interdisciplinares na área da educação.

No que se refere à inclusão escolar, considera-se que esta requer um compromisso coletivo para acontecer efetivamente nos diferentes ambientes sociais e, neste sentido, a visão interdisciplinar torna-se fundamental para que o convívio social possa acontecer naturalmente. 
Direção, professores, funcionários e familiares deveriam conhecer e estudar princípios e práticas que possam oportunizar ações em torno de uma proposta interdisciplinar nas situações escolares.

Ao longo de décadas, a ciência desenvolveu, partindo do pressuposto cartesiano, a noção de especialização, por meio da criação de novas profissões e com a adoção de um novo sistema de ensino e de formação, fundamentado na disciplinaridade. A ciência avançou e o paradigma cartesiano mostra sinais de esgotamento. Nesse contexto, a interdisciplinaridade conquista seu espaço como uma alternativa para a substituição do jeito de se produzir e transmitir conhecimento, visando superar a visão disciplinar (VILELA; MENDES, 2003).

O conceito de interdisciplinaridade foi construído através das implicações decorrentes dos questionamentos da concepção de disciplinaridade, no entanto, vem sendo discutido desde os anos 70 .

De acordo com Japiassú,

Nesse contexto, o esforço de integração da interdisciplinaridade se apresenta como o remédio mais adequado à cancerização ou à patologia geral do saber. A interdisciplinaridade se caracteriza pela intensidade das trocas entre os especialistas e pelo grau de integração real das disciplinas no interior de um mesmo projeto de pesquisa. (JAPIASSÚ, 1976, p.30).

É importante ressaltar que a interdisciplinaridade baseia-se antes de tudo, na relação entre pessoas, o que implica nos problemas contidos em todas as relações interpessoais.

Dessa forma, verifica-se que:

A interdisciplinaridade é considerada uma inter-relação e interação das disciplinas a fim de atingir um objetivo comum. Nesse caso, ocorre uma unificação conceitual dos métodos e estruturas em que as potencialidades das disciplinas são exploradas e ampliadas. Estabelece-se uma interdependência entre as disciplinas, busca-se o diálogo com outras formas de conhecimento e com outras metodologias, com objetivo de construir um novo conhecimento. Dessa maneira a interdisciplinaridade se apresenta como resposta à diversidade, à complexidade e à dinâmica do mundo atual. (VILELA E MENDES, 2003, p. 529).

No entanto, mesmo diante do consenso de teóricos como Japiassú (1976), Vilela e Mendes (2003), entre outros, a respeito da relevância da interdisciplinaridade como ferramenta para a evolução dos profissionais e, principalmente, dos educandos - a que são destinados os projetos interdisciplinares - é possível observar que foram produzidos avanços que acarretaram em reflexos significativos a respeito da interdisciplinaridade no cotidiano educacional brasileiro.

É no dia a dia escolar que as crianças, enquanto atores sociais, têm acesso aos diferentes conteúdos curriculares, os quais devem ser organizados de forma a efetivar a aprendizagem. Para que esse objetivo seja alcançado, a escola precisa ser organizada de forma a garantir que cada ação pedagógica resulte em uma contribuição para o processo de aprendizagem de cada aluno.

É necessária uma ruptura com os muros que dividem e fragmentam o saber em diferentes áreas, estanques entre si, muros que têm sido criticados pela excessiva parcialização de cada competência disciplinar, como se fosse possível isolar uma parte organicamente integrante de um todo. Para Santos (1997, p. 46) "a excessiva disciplinarização do saber científico faz do cientista um ignorante especializado".

Escola inclusiva e interdisciplinar é aquela que garante a qualidade de ensino educacional a cada um de seus alunos, reconhecendo suas potencialidades e necessidades. Assim, uma escola somente poderá ser considerada inclusiva quando estiver organizada para favorecer a cada aluno, independentemente de etnia, sexo, idade, deficiência, condição social ou qualquer outra situação, 
um ensino significativo. Ensino significativo e interdisciplinar é aquele que garante o acesso ao conjunto sistematizado de conhecimentos como recursos a serem mobilizados (FAZENDA, 1993),

Numa escola inclusiva, o aluno é sujeito de direito e foco central de toda a ação educacional. Desse modo, garantir a sua caminhada no processo de aprendizagem e de construção das competências necessárias para o exercício pleno da cidadania é, por outro lado, objetivo primeiro de toda ação educacional.

A escola inclusiva é quela que conhece cada aluno, respeita suas potencialidades e necessidades, e a elas responde, com qualidade pedagógica.

Para que uma escola se torne inclusiva há que se contar com a participação consciente e responsável de todos os atores que permeiam o cenário educacional: gestores, professores, familiares e membros da comunidade na qual cada aluno vive.

\section{METODOLOGIA DA INVESTIGAÇÃO}

Para realizar esta pesquisa, adotou-se uma abordagem qualitativa. Como estratégia utilizou-se um estudo de caso, realizando observações a respeito de uma aluna com NEE-SD em aulas do ensino regular.

A pesquisa qualitativa, segundo Leal e Souza (2006, p. 17), "considera que há uma relação dinâmica entre o mundo real e o sujeito, isto é, um vínculo indissociável entre o mundo objetivo e a subjetividade do sujeito que não pode ser traduzida em números". Em relação ao uso do estudo de caso, Yin (1989, apud LEAL; SOUZA, 2006, p.30) afirma que:

[...] o estudo de caso é uma inquirição empírica que investiga um fenômeno contemporâneo dentro de um contexto da vida real, quando a fronteira entre o fenômeno e o contexto não é claramente evidente e onde múltiplas fontes de evidência são utilizadas.

A aluna investigada tem 15 anos, apresenta Necessidades Educacionais Especiais Síndrome de Down e encontra-se no segundo ano de uma Escola Municipal do Ensino Fundamental de São Gabriel, no Estado do Rio Grande do Sul.

Durante a investigação foram observadas e analisadas as formas de interação da aluna com os conteúdos desenvolvidos, quais as metodologias empregadas pela professora e pela monitora para que ela desenvolva as atividades, bem como sua motricidade e os registros diários em seu caderno de atividades.

Foi realizado um acompanhamento diário durante um mês, observando as reações e o desenvolvimento cognitivo e sua evolução durante as aulas. A direção da escola autorizou que a pesquisadora observasse, por duas horas diárias, durante quatro semanas, o desempenho da aluna em sala, para não interferir no andamento das aulas. O objetivo era analisar como uma criança com Síndrome de Down desenvolve seus conhecimentos no ensino regular. Também se observou os seguintes aspectos: a metodologia empregada pela professora para trabalhar com a aluna; interação professora-aluna e aluna-professora, se as atividades são condizentes com a capacidade cognitiva da aluna e se há inclusão da aluna nas atividades.

Enquanto a aluna desenvolvia suas atividades com o auxílio da monitora, suas atitudes, comportamentos e reações frentes às mesmas eram observadas pela pesquisadora, que se sentava ao lado dela sem interferir, registrando no Diário de Bordo as observações que considerou pertinentes aos objetivos da pesquisa 
Após o período de observação e anotações no Diário de Bordo, foram feitas as análises, tendo como base os fundamentos estudados no curso quanto a processos interdisciplinares para o desenvolvimento cognitivo da aluna.

\section{ANÁLISE DOS DADOS}

Sara $^{2}$, portadora da Síndrome de Down, tem quinze anos e é uma menina alegre, desinibida, que gosta muito de música, gosta de fazer carinho nas pessoas com as quais ela simpatiza e assegura que adora estudar. Possui uma boa situação financeira e muito apoio por parte dos pais.

As observações ocorreram no mês de abril de dois mil e onze.

Ela foi observada durante as aulas de ensino globalizado do segundo ano do Ensino Fundamental, quando estava presente nas aulas com os colegas - crianças com idade entre oito e nove anos, em uma turma de vinte e três alunos. Percebeu-se que ela não participa de forma atuante nas aulas, não interage com o conteúdo, pois não entende o que está sendo desenvolvido. Sua participação na aula é nula, isto é, ela não se manifesta nem acompanha os colegas nas leituras orais. Necessita de uma acompanhante $\left(\right.$ monitora $^{3}$ ) para poder realizar as atividades e mesmo assim, não são todas as atividades propostas pela professora que ela consegue fazer. Contudo, no relacionamento pessoal com os colegas é bem participativa, inclusive nas brincadeiras em momentos de recreação.

Durante a realização das atividades apresentas pela professora, observa-se reações e sentimento dela frente às atividades propostas. Sua postura é quase sempre a mesma: aparentemente calma, sem demonstrar felicidade, ou sinal de cansaço, mas, às vezes, demonstra desinteresse. Nas atividades com maior grau de dificuldade para ela, como a escrita de palavras ou colorir desenhos, apresenta um sentimento de chateação, pois argumentava que não gostava de pintar.

Quando ela demonstrava esse tipo de atitude a monitora (acompanhante), a incentivava auxiliando-a na execução da tarefa solicitadas pela professora. A monitora usava palavras de incentivo, falando baixinho e sempre questionando se estava entendendo a atividade, buscando identificar as dificuldades manifestadas por Sara.

Em contrapartida, as atividades de cobrir pontinhos, ligar nomes aos desenhos ou desenhos entre si, entre outras, ela considerava fácil e as realizava mesmo sem a intervenção da monitora. Quando acertava as atividades sorria e dizia que era fácil e que ela sabia tudo.

Em outra ocasião, a professora entregou folhas com o desenho de três ursos enfileirados para localizar o que ia à frente. A menina observou o desenho " reconheceu o urso e identificou corretamente o que vai à frente", o mesmo ocorreu quando teve que identificar o passarinho que voava atrás: "Reconheceu o pássaro e identificou o que voa atrás", conforme notações feitas pela pesquisadora.

Seguindo as atividades, a monitora desenhou em seu caderno elementos para que ela contasse. Obteve sucesso na contagem até cinco elementos.

$\mathrm{Na}$ atividade em que era necessário reconhecer as vogais, obteve sucesso total, fazendo a relação vogal-desenho iniciado pela vogal. No entanto para fazer a ligação necessitou da ajuda da monitora. Depois coloriu os desenhos segurando sozinha o lápis.

\footnotetext{
${ }^{2}$ Nome fictício

${ }^{3}$ A monitora é uma acadêmica de Pedagogia, sem experiência com a inclusão. 
Dentre as atividades que a Sara realizou, é importante destacar aquelas que mais apresentaram grau de dificuldade foram: formar palavras, separar sílabas. Ela demonstrou não possuir coordenação motora desenvolvida para pintar, conforme o esperado para uma criança no segundo ano do Ensino Fundamental.

Nas demais atividades, que envolvem quantidades, contagem, reconhecimento do número, apresentou um bom desempenho na contagem, mas não grafava os números. Quando apresentada à menina situação em que precisou contar elementos, fez oralmente, mas não conseguiu grafar os números, ou seja, não estabelece a relação entre a quantidade e o símbolo.

A professora desenvolve atividades constantes nas quais é necessário identificar e grafar vogais, ou contar quantidades e grafar os números. No entanto, observou-se que a menina responde bem oralmente, mas no momento da escrita ela não consegue realizar as tarefas, nem com a ajuda da monitora.

A professora usa um número expressivo de folhas fotocopiadas para que os alunos realizem atividades semelhantes como identificar vogais, ligar vogais, ou contar quantidades. Não existe diversidades e nem integração entre os exercícios. Muito deles ficam em branco, porque a menina se recusa a fazer ou simplesmente rabisca sobre eles. O conhecimento da jovem é manifestado basicamente pela oralidade.

A monitora interferia constantemente na realização das atividades, pois a aluna em questão, não entendia o que era para fazer e não se determinava, permanecendo muitas vezes em silêncio ou perguntando para a monitora o que deveria fazer. Essas intervenções, além de serem constantes, eram necessárias para manter a atenção da aluna focada nas atividades exigidas na sala de aula.

O que se observa neste ambiente de sala de aula que não há essa flexibilização curricular. É como se houvesse duas propostas pedagógicas. Uma direcionada aos alunos ditos "normais" e outra à jovem com Síndrome de Down. Embora os conteúdos sejam os mesmos, não existe algo diferenciado para atender às suas necessidades de entendimento e representação do conteúdo escolar. Tanto é que, se não fosse o auxílio permanente da monitora ela não realizaria nenhuma atividade em sala de aula. Assim, ela se encontra afastada das demais crianças, mesmo estando dentro da sala de aula, não sendo integrada ao contexto da prática pedagógica. Ela trabalha isoladamente somente com o auxílio da monitora.

Por esse motivo é que se deve ter em mente que a escola inclusiva vem ao encontro do que se almeja em termos de educação e de sociedade, como um todo, pois é, segundo Carvalho (2008, p. 12) "uma escola para todos, com todos, mas uma escola que, além da presença física, assegure e garante aprendizagem e participação".

Neste caso, durante a observação não se constatou nenhum diálogo da professora com a monitora em relação às dificuldades da jovem. Embora exista na escola uma Sala de Recursos ${ }^{4}$ na qual a jovem tem atividades em turno inverso, não existem evidências de que haja um diálogo entre a professora da classe e a da Sala de Recursos para realizar um atendimento mais adequado às necessidades da jovem.

Portanto, entende-se que, além de ser uma escola inclusiva, é necessário que atue dentro de uma perspectiva interdisciplinar. Sendo este o grande desafio posto na atualidade para que a escola assuma um lugar de construção do conhecimento e, para tanto, a perspectiva interdisciplinar tem sido apontada como elemento de coesão dos diferentes saberes em torno de uma aprendizagem significativa.

\footnotetext{
${ }^{4}$ Sala de Recursos - Sala na qual os alunos recebem um tratamento individualizados e que são trabalhadas suas habilidades.

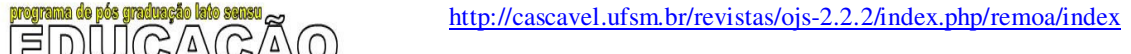




\section{CONSIDERAÇÕES FINAIS}

Este artigo, além de descrever como acontece o processo de escolarização de uma aluna com Síndrome de Down, trouxe também contribuições teóricas para um melhor entendimento sobre o tema.

As observações realizadas mostram que é importantes os professores atuarem interdisciplinarmente para que pessoas com Síndrome de Down sejam escolarizadas de forma adequada, principalmente no que se refere à aquisição de conhecimentos da linguagem oral e escrita e da matemática.

Deve-se, constantemente, fazer uma retomada do conteúdo já estudado, pois é através do reforço que as pessoas com síndrome de Down conseguem acumular conhecimentos. De acordo com Schwartzman (2007), eles apresentam um atraso mental, e por isso, o reforço do que já foi dito, estudado, trabalhado, vem ao encontro do que se deseja, que é a aquisição do conhecimento sobre os conteúdos estudados.

Ao realizar as observações para realização do trabalho de pesquisa, verificou-se, que a escola onde a aluna está inserida, não está inclusiva para essa aluna, conforme o que Carvalho (2008) define, pois ela não está recebendo uma formação adequada de acordo com suas dificuldades (exercícios apenas de memorização e repetição). Isso porque, além de estar incluída socialmente, ela precisa, ela precisa, e muito, de um acompanhamento especializado para que possa desenvolver a coordenação motora para poder grafar corretamente, pois oralmente ela consegue expressar seu conhecimento. Apresenta grande dificuldade, especificamente na coordenação motora.

No entanto, observou-se que seu conhecimento se manifesta basicamente pela oralidade. Ela responde aos questionamentos com pronúncia correta das palavras e, inclusive, com argumentos que justificam suas respostas.

É aceitável que ela não acompanhe as aulas do segundo ano do ensino Fundamental com seus colegas de sala de aula, pois apresenta limitações na coordenação e na memorização das palavras, cores e números. Por esse motivo, seria interessante um trabalho mais voltado ao lúdico com materiais concretos, pois através da observação pode-se perceber que ela trabalha com mais interesse quando pode manipular objetos ou jogos pedagógicos.

Outro fato que ficou evidente é que a professora não desenvolve suas aulas na perspectiva da interdisciplinaridade, pois não estabelece diálogo com outros profissionais. Talvez por algum tipo de receio ou até como forma de autoproteção, de segurança, ela não abre os conteúdos ao diálogo para troca equitativa entre eles.

Sabe-se que um projeto/enfoque interdisciplinar não é ensinado, mas vivenciado, e exige, para tanto, a responsabilidade individual, ao mesmo tempo em que exige envolvimento com as instituições, com as pessoas. Essa prática do diálogo com outras áreas do conhecimento permite perceber, sentir e pensar de forma interdisciplinar, exigindo a quebra de barreiras e ousadia para inovar e criar, como muito bem lembra Fazenda (1993).

Assim, constatou-se que a aluna com Síndrome de Down, embora recebendo um atendimento individualizado, não está incluída na turma, pois realiza suas atividades de maneira isolada, contando com o auxílio da monitora. Acredita-se que seria importante que a professora realizasse atividades de socialização em que a jovem tivesse que interagir com os colegas na realização das tarefas.

Fica evidente, que é necessário um eixo articulador em torno do qual seja possível o diálogo entre as diferentes disciplinas e suas respectivas abordagens, porque, embora o ensino no segundo ano do Ensino Fundamental seja globalizado, as disciplinas continuam fragmentadas. 
Esta pesquisa contribuiu para que ficasse evidente que o processo de inclusão escolar e a abordagem interdisciplinar ainda estão longe de acontecer, na concepção da educação inclusiva e interdisciplinar em nossas escolas. Ressalta-se que acriança com Síndrome de Down, dentro das suas limitações, tem condições de se desenvolver cognitivamente, desde que receba uma educação adequada e voltada às suas necessidades.

Este trabalho traz a certeza de que a inclusão escolar não se realiza apenas por discursos e vontade política. Sua concretização incide em mudanças estruturais nas concepções e práticas que norteiam o currículo escolar, implicando a ação de pais e familiares, de professores e equipe técnico-pedagógica e dos órgãos centrais da educação em um esforço comum na remoção de barreiras atitudinais, como o medo e o preconceito, e de barreiras à aprendizagem.

Este trabalho também levou a outra constatação, a de que construir conhecimentos numa perspectiva interdisciplinar é um paradigma que deve ser vencido pelos professores. A interdisciplinaridade é uma proposta educacional que se vê na literatura, nos planos de trabalho, mas que na prática não está sendo executada.

\section{REFERÊNCIAS BIBLIOGRÁFICAS}

BISSOTO, M. L. Desenvolvimento cognitivo e o processo de aprendizagem do portador de síndrome de Down: revendo concepções e perspectivas educacionais. Ciência \& Cognição, v. 04, p.80-88, mar. 2005. Disponível em: <http://www.cienciasecognicao.org/pdf/v04/m11526.pdf> Acesso em: 02 dez 2011.

BOCHNIAK, Regina. Questionar o conhecimento: interdisciplinaridade na escola. 2.ed. São Paulo: Loyola, 1998

BRASIL. Parâmetros Curriculares Nacionais: Língua Portuguesa. Brasília: Ministério da Educação, 2001, v.2. 144p.

- Ministério da Educação. Diretrizes Nacionais para a Educação Especial na Educação Básica. Secretaria de Educação Especial. MEC; SEESP, 2001.

CARVALHO, R. E. Escola Inclusiva: a reorganização do trabalho pedagógico. Porto Alegre: Mediação, 2008. 152p.

CUSIN, D.A. et al. Avaliação do processo receptivo: investigação do desenvolvimento semântico em indivíduos com Síndrome de Down. Revista Brasileira: Educação Especial, v 11, n. 1, p.81-96, jan./abr. 2005.

FAZENDA, I. C. A. Práticas interdisciplinares na escola. São Paulo: Cortez, 1993.

GOTTI, M. Integração e Inclusão: nova perspectiva sobre a prática da Educação Especial. In: MARQUEZINE, M. et al. (coord.) Pesquisas multidisciplinares em Educação Especial. Londrina: UEL, 1998.

JOAQUIM, M. F. A inclusão de alunos com Síndrome de Down. Revista Brasileira de Educação Especial, vol. 12, ano 1, Marília, São Paulo, jan/abril, 2006.

LEAL, A. E. M.; Souza, C. E. G.. Construindo o conhecimento pela pesquisa: orientação básica para elaboração de trabalhos científicos. Santa Maria: Sociedade Vicente Pallotti, 2006.

LIMA, R. de C. P.; FERRAZ, V. E. F. Saúde-doença, normalidade-desvio, inclusão-exclusão: representações sociais de Síndrome de Down em um centro de Educação Especial e Ensino Fundamental. Ribeirão Preto: Universidade de Ribeirão Preto, 2000.

LUFT, C. P. Língua e Liberdade (o gigolô das palavras): por uma nova concepção da língua materna. Porto Alegre: L\&PM, 1985. 
MANTOAN. M. T. E. A integração de pessoas com deficiência: contribuições para uma reflexão sobre o tema. São Paulo, Memnon, 1997.

MATTOS, S. M. N. A afetividade como fator de inclusão escolar. TEIAS. Rio de Janeiro, ano 9, no 18, p. 50/59, julho/dezembro, 2008. Disponível

em:

$<$ http://www. periodicos. proped.pro.br/index.php?journal=revistateias\&page=article\&op=viewFile\&path\%5B\%5D=27

1\&path\%5B\%5D=283>. Acesso em 12 jan 2012

MOELLER, I. Diferentes e Especiais. Rev. Viver Mente e Cérebro, n. 156, p. 26-31, jan.,2006.

NEVES, I. C. B. et al. (Org.). Ler e escrever: compromisso de todas as áreas. 5.ed. Porto Alegre: Editora da universidade/ UFRGS, 2003.

SANTOS, B. Um discurso sobre as ciências. 9.ed. Porto Edições Afrontamento, 1997.

SCHWARTZMAN, José S. et al. Síndrome de Down. São Paulo: Memnon, 2007. 324p.

WERNECK, C. Muito prazer, eu existo: um livro sobre as pessoas com Síndrome de Down. 4 ed. ver. Rio de Janeiro: WVA, 1995. 